\title{
Key Performance Indicators for Influencer Marketing on Instagram
}

\author{
Claudia Primasiwi ${ }^{1, a)}$, M. Isa Irawan ${ }^{2, \text { b) }}$, Rita Ambarwati ${ }^{3, c)}$ \\ ${ }^{1}$ Department of Technology Management, Institut Teknologi Sepuluh Nopember, Surabaya, Indonesia. \\ ${ }^{2}$ Department of Mathematics, Institut Teknologi Sepuluh Nopember, Surabaya, Indonesia \\ ${ }^{3}$ Faculty of Business Law and Social Science, Universitas Muhammadiyah Sidoarjo, Sidoarjo, Indonesia. \\ ${ }^{a)}$ Corresponding author: claudiaprimasiwi@gmail.com \\ b) mii@its.ac.id \\ c) ritaambarwati@umsida.ac.id
}

\begin{abstract}
The emerging field of information technology has been going through a drastic shift since social media this decade. Social media has become a new medium to share information and news rapidly. The swift flow of information in social media causes a new phenomenon called 'social media influencer.' The marketing team also uses the popularity of influencers in social media to expand their appeal to consumers. However, selecting influencers for a marketing campaign is the second largest issue found in digital marketing activity. Besides, influencer frauds is a common practice that results in the ineffectiveness of a marketing campaign. Therefore, carefully assessing the influencer for a marketing campaign is necessary. This research aims to find out what kinds of key performance indicators can be used to assess influencers before collaborating with them. Also, this research explores the most important KPI in Indonesia's influencer marketing scene. This research finds there are $11 \mathrm{KPI}$ found that can be used to pre-evaluate the influencers. According to digital marketing practitioners in Indonesia, the three most important KPI are followers, like-comment ratio, and audience reachability. This shows that marketing practitioners do not merely see a high number of followers for selecting influencers, but also their interaction authenticity to prevent influencer fraud.
\end{abstract}

Keywords: Social Media Marketing, Influencer Marketing, Key Performance Indicators.

\section{INTRODUCTION}

As the result of the emergence of information technology, the internet transforms the way people communicate throughout the world. The invention of smartphones accelerates easier access to the internet, resulting in the rise of social media usage. Nowadays, social media becomes a platform to exchange information among individuals and businesses. By 2021 , the number of social media users in Indonesia increased by 10 million $(+6.3 \%)$ between 2020 and 2021. This makes up $61.8 \%$ of the total population in Indonesia is active social media users. In addition, the same study shows the percentage of internet users aged 16 to 44 that discovers new brands or products, $39.2 \%$ of internet users discovers from an advertisement on social media while $39 \%$ discovers from recommendation or comments on social media [1]. This large number has created an expansive potential marketing media known as social media marketing. Social media marketing exploits the users' participation to advertise products, services, brands, or issues such as political campaigns. As social media develops, the swift information exchange in social media causes a phenomenon called social media influencers.

A social media influencer is an individual who has a massive influence on social media. The marketing professionals are utilizing the influencers to expand its marketing scope, known as influencer marketing. Influencer marketing benefits from influencers with 
high influence on social media to affect either consumers' brand awareness or purchase intention [2]. In Indonesia, the budget spent on social media advertising in 2020 reached $\$ 439.2$ million, increasing $14.4 \%$ from the previous year. From the same study, consumers in Indonesia are more familiar with online transactions and convenience, compared to some other regions in Asia [1]. These aspects have combined to create a competitive marketing environment for an influencer in Indonesia.

However, it is still a challenge for businesses to choose the right influencers. Determining influencers for digital marketing has been made on the basis of performance indicators called metrics. Another challenge in influencer marketing is influencer fraud, particularly in Instagram. Influencer fraud is an activity where influencers purchase fake followers, likes, or comments to deceive the businesses. The influencer fraud arises from the fact that engagement has been highlighted as a key measure of influencer marketing success. This means, having a large number of followers does not necessarily make an influencer an opinion leader [3]. Another study shows that the number of followers cannot be a sufficient predictor to measure the effectiveness of a digital marketing campaign [4].

Based on the explanation above, this research aims to determine the key performance indicators (KPI) that are needed in order to select the right influencer for a marketing campaign.

\section{CONCEPTUAL BACKGROUND}

Marketing in Social Media: Social media is described as a collection of a web-based application that builds on Web 2.0's ideological and technological foundations, enabling user-generated production and consumption [5]. Social media networking is also defined as highly interactive media that enables discussions, reciprocation, and the generation of content by individual or community users [6]. People see social media as an important part of their everyday lives, thus social media has a major impact on aspects of people's lives, such as social, educational, commercial, and business aspects. [7] [8] [9] [10] [11] [12]. Marketing activities in social media marketing must be in line with the marketing strategy of a company and consistent with it. Social media marketing should distribute information as quickly as possible to the smartphones of people with an extrawide regional scope as a new kind of word of mouth (WOM or e-WOM). Marketing on social media offers two-way communication between content creators or marketers and their target market. To measure marketing performance on social media, Key Performance Indicators (KPI) with distinct terms across platforms are used (e.g., 'Followers' on Instagram and 'Subscribers' on YouTube). Marketing in social media provides various benefits, but social media is famous primarily because marketers benefit from exposure on social media sites [13].

Influencer Marketing: Online individuals with a great number of followers on one or more social networking sites identified as social media influencers or better known as influencers. The difference between influencers and celebrities is that influencers are "ordinary people" who become "online celebrities." Influencers generally have expertise or niche in different fields as opposed to celebrities [14]. Twitter research reveals that followers trust influencers like their own friends [15]. Digital marketing practitioners utilize this for promotion because of the trust that influencers gain from their large audience. Influencer marketing refers to a marketing strategy that involves investing in an influencer to create and promote their content to the subset of followers of the influencer and the target audiences of the company. As a consequence of digitalization, there has been a change in customer behavior. Consumers depend on a person, such as an influencer, to find the right information to help them make purchase decisions [13]. This is what drives influencer marketing has grown rapidly and become a major part of the marketing world in general. This attractiveness is due to the reputation that influencers have in the eyes of their followers and the ability of influencers to grow followers into loyal customers. In $2018,63 \%$ of brand marketers collaborated with at least 10 influencers to support their goods and services [16].

For decades, long before digital marketing existed, the notion of marketing using famous people who can impact people's viewpoints has been around. Influencer marketing today refers to the use of social media by non-celebrities to promote the product or service of a brand [17]. The advantage of influencer marketing is that advertisers can hire influencers at relatively more affordable rates than well-known celebrities. The way the message is delivered is the major difference between influencers and celebrities. Influencers create their material for their fans, unlike celebrities. Influencers are also very accessible to their audience's input, creating a two-way interaction between the influencer and the audience [18].

Marketing in Instagram: Instagram is one of the most used social media in the world that is widely known for image sharing. By 2020, Instagram reaches one billion users [1]. Users spent an average of 30 minutes per day on the platform in 2020 [19]. As a photo-sharing social media site, Instagram promotes visual content trends preferred by advertisers in social media marketing [20]. Marketing teams use a measurable value called metrics to demonstrate the effectiveness of a digital campaign. Instagram offers a variety of metrics to evaluate the performance of a profile. Level-one metrics are specific numbers such as followers, likes, and comments. Level-two performance metrics are all about calculated metrics using available data as the benchmark [21]. 


\section{METHOD}

This research consisted of two main stages: Finding the quantitative and qualitative metrics for influencer selection and finding the most important metrics for influencer selection according to marketing practitioners in Indonesia.

Research Design and Data Collection: This research focused on influencer marketing campaigns targeted at the Indonesian audience. First, this research reviews some works of literature to identify the metrics that will be considered in selecting influencers. Second, a questionnaire will be given to Indonesian marketing practitioners that are working in the field of social media marketing (e.g., brand managers, public relations managers); employees who work in digital marketing agencies, especially in marketing on social media; as well as online shop owners who have used influencer services for promotions on Instagram more than once, assuming the online shop owner able to compare the impact of the promotion.

There were 107 respondents involved, consisting of 44 digital marketing staff, 24 social media officers, 25 online shop owners who had conducted digital promotions with influencers, eight marketing communication staff, three public relations staff, and three digital agency staff. The questionnaire was consisting of 18 questions, comparing the importance scale of each KPI with the others in the same category. The results of the questionnaire are figures based on the importance on a scale of 1 to 9 . The higher the level of importance given, the higher the degree of importance. The results of the questionnaire are then processed by combining the results of all values from the respondents giving them into the geometric mean calculation.

Pairwise Comparison: Pairwise comparison assessments done by more than one participant can result in different assessments from each respondent. The assessment has to be merged into one pairwise comparison value to achieve a value that reflects all the outcomes of the assessment. The merger is achieved by finding the average value of all the assessment results. Generally, there are two types of averages: arithmetic means and geometric mean. The arithmetic average is used when the measured data is data with an interval or ratio scale that has a constant distance for each data, all values are involved in the process of calculating the average, the average is unique because there is only 1 average in the data set, and the sum of the deviation of each value from the mean is 0 . Meanwhile, the geometric mean is useful in finding the average of percentage, ratio, index with a distance that is not necessarily constant for each data [22]. Pairwise comparisons are done by making a pairwise comparison matrix, where the aij value represents the relative importance of the elements in a row (i) to the elements in column $(j)$, for example, aij $=$ wi $/$ wj. If $n$ elements are being compared, the comparison matrix a can be defined as in Equation 1.

$$
a=\left(\begin{array}{llll}
\frac{w_{1}}{w_{1}} & \frac{w_{1}}{w_{2}} & \ldots & \frac{w_{1}}{w_{n}} \\
\frac{w_{2}}{w_{1}} & \frac{w_{2}}{w_{2}} & \ldots & \frac{w_{2}}{w_{n}} \\
\frac{w_{n}}{w_{1}} & \frac{w_{n}}{w_{2}} & \ldots & \frac{w_{n}}{w_{n}}
\end{array}\right)=\left(\begin{array}{cccc}
\mathbf{1} & a 12 & \ldots & a 1 n \\
a 21 & \mathbf{1} & \ldots & a 2 n \\
\ldots & \ldots & \ldots & \ldots \\
a n 1 & a n 2 & \ldots & \mathbf{1}
\end{array}\right)
$$

After all pairwise comparisons have been made, the priority weight vector $(\mathrm{w})$ is calculated using Equation

$$
A_{w}=\lambda_{\max } W
$$

The Consistency Index (CI) and Consistency Ratio (CR) of the pairwise comparison matrix can be calculated using Equation 3 and Equation 4

$$
\begin{gathered}
C I=\frac{\lambda_{\max }-n}{n-11} \\
C R=\frac{C I}{R C I}
\end{gathered}
$$

2 where $\lambda \max$ is the largest eigenvalue in matrix $A$ and $\mathrm{w}$ is the eigenvector.

respectively. The judgment will be considered consistent if the CI value is $<0.1$. 


\section{RESULT AND DISCUSSION}

Instagram Metrics: The Instagram metrics used for judgments were used in this research to determine the community and the engagement of the influencer. Influencer marketing adapts the WOM concept, which includes the method of finding and choosing prominent users to enable them to support a brand or a particular product through their social media activities [3]. WOM communication takes place in a particular forum or in a networking platform in a digital context [23]. The audience of influencer marketing is the followers on their Instagram that the influencer has. The greater the number of followers that an influencer has, the greater the influence. Marketers need to look at variables other than follower numbers, such as the breadth of reach and audience authenticity, to prevent influencer fraud. The effectiveness of promotion by the use of influencers is still uncertain since the marketing industry for influencers is still unregulated. Marketers often have ways to determine the effectiveness of digital marketing campaigns across different media by looking at the number of interactions of the promoted content. Marketers may also prevent being cheated by influencers who buy fake followers or fake interactions by paying attention to interactions (likes and comments).

Community Size (Followers): Community size, which refers to the number of followers an influencer has, is one of the baselines for choosing influencers. Some people use the number of followers to assess a person's popularity. The more followers, the more appealing the influencer is to society. Popular Instagram users would look more appealing, open, trustworthy, friendly, and have other desirable social characteristics [24] [25] [26].
Audience Reachability: One of the key objectives of marketing is to reach consumers before, during, or after purchasing something, impacting its success [27]. Audience reachability refers to the percentage of followers among the audience who can see the influencer's content in their feed. Audiences that follow fewer than 1,500 accounts would be classified as reachable by influencers. The fewer profiles the viewer follows, the higher the likelihood that the digital marketing promotion will be seen by the audience [28].

Audience Authenticity: There are several services that allow people to purchase and sell Instagram followers at relatively cheap prices to raise followers. There are five categories of accounts on Instagram: real, influencers, mass followers, commercial, and suspicious accounts. An account is listed as an influencer if it has more than 5,000 followers. Mass followers follow more than 1,500 users, which usually uses automated software to follow other accounts for followers. Meanwhile, suspicious accounts are bot accounts or use certain sites to get followers, comments, or likes. It is important to assess the authenticity of the viewer to avoid the selection of a fraudulent influencer. The audience's authenticity points to the percentage of the total audience that is genuine [29].

Like and Comment Ratio: According to an analytic platform, Hypeauditor, the number like-comment ratio determines if an Instagram user has more comments or likes. A significant disparity in the number of likes or comments indicates that the user artificially gets them. If an Instagram user buys the same amount of likes and comments, the dots in Figure 3 will be clustered in one location. On the other side, an uneven distribution of dots may mean that the Instagram user has organic involvement.

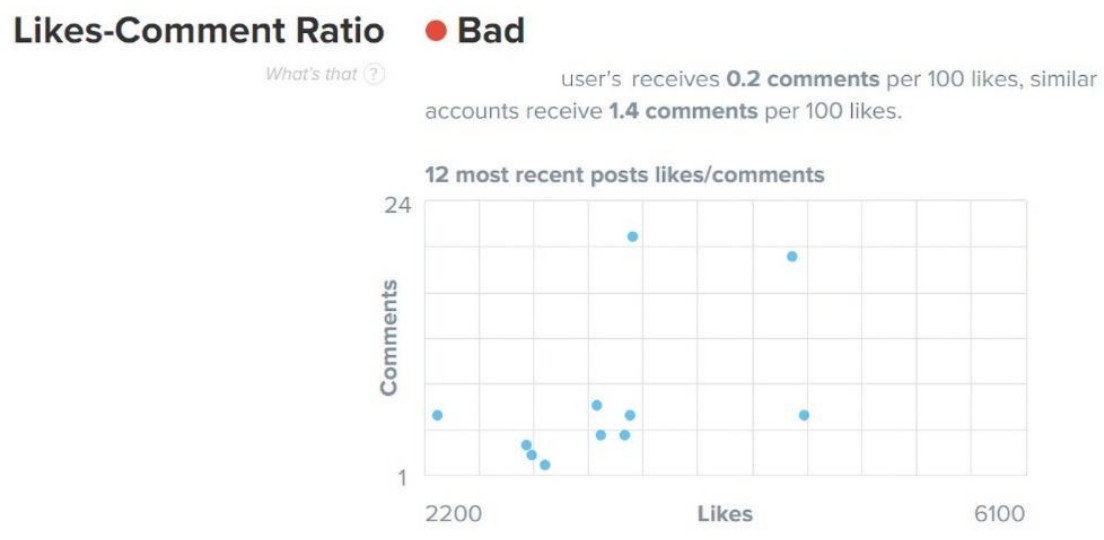

Figure 1 Like-Comment Ratio Visualisation [30]

Like Spread: According to trendHERO, the amount of like-spread shows the disparity in the number of likes from the last few uploads. The typical like-spread percentage varies between 40 percent and 100 percent. Low distribution of like-spread means that the influencer may have artificially raised the amount of like in one or more posts by buying likes. In the meantime, if the distribution of likes exceeds 100 percent, it means that there is an effort to increase the number of likes by paying for posting (advertised post) or giving away. In general, followers would like one post over another because of the particular desires of each post. Thus, influencers with the same number of likes in each upload are regarded with suspicion [31]. 
Engagement Rate: The level of engagement represents the level of communication with the viewer. The higher the degree of communication, the better. A low degree of engagement implies that the viewer dislikes the posted content and explains that most of the account followers are bots or inactive users. There are two methods to quantify the engagement rate, respectively measuring the Post Engagement Rate and the Overall Engagement Rate. The Post Engagement Rate compares performance between uploads, while the Average Engagement Rate compares engagement between accounts. In this analysis, the Average Engagement Rate was used as a measure between influencers. The steps to calculate the Post Engagement Rate can be done by adding up the likes and comments on the posts at a certain interval, as seen in Equation 5.

$$
\text { Average Engagement Rate }=\frac{\frac{\text { Likes }+ \text { Comments }}{\text { Followers }}}{\text { Count of Posts }} \times 100 \%
$$

Rate Card: The rate card is a breakdown of the advertising company's marketing costs, both in print and electronic media. The study reveals that brand alignment is the most important factor, followed by budgetary issues in influencer selection. The justification is that the influencers have something in common with a corporation's resources, i.e., an expansion of the business to the public so a calculated budget is needed [32].

Value of Influencers: Influencers can help to boost reputation by sharing content through their social media sites. The approach to assessing influencers is a complex process because all considerations affect the outcome. The number of posts, subscribers, social structure, and company goals using influencers may be among these aspects [33]. Studies suggest that the same message conveyed by different influencers can be viewed differently by followers; this is affected by numerous influencers' factors [34].

Relevance: The first thing to do is see how the influencer will represent a brand or organization to pick an influencer. The influencer's relevance is seen from different factors such as appearance, the form of content produced, and the target audience [35]. A social media manager at a marketing agency indicated that the agency will reflect on how important an influencer is to a company or brand and check at the influencer's past work with businesses to determine whether the influencer is appropriate to work with [32].

Authenticity: Consumers get numerous commercials in their daily lives, whether they are the commercials they are looking for or not. The overflowing information of advertisements causes consumers to be wary of ads so that consumers build tactics to stop advertisements, known as 'consumer resistance.' By making advertisements real, advertisers can counter customer resistance and make marketing objectives succeed. Authentic messaging has the characteristics of true, actual, and authentic [36]. Authenticity increases the reception of messages transmitted by advertisers [37], increases perceived value [38], and also increases purchase intention [39]. Authentic influencers are most likely to have a committed audience. By being experts in subjects they mastered, they would grow their viewers' loyalty and trust. Authentic influencers illustrate their expertise via various original and personal stories, tips, and advice.
The caption on the post, both not sponsored and sponsored posts shows an influencer's authenticity. The caption on the message, both not sponsored and sponsored posts shows an influencer's authenticity. The influencer's caption should assist its audience for the endorsed brand. Influencers will illustrate that they promote the company's product or service, how to use it, and why they love the brand.

Content Quality: Influencers often have multiple competencies that are key to creating successful social media content. Many influencers may develop their own visual and narration models [40]. Collaborating with influencers involves granting influencers innovative autonomy to produce content endorsed by a brand. Since influencer content will represent a brand, evaluating if the quality of their content is appropriate for the brand profile before committing to do a digital marketing campaign is a source of concern. Any aspects to pay attention to about influencer content are descriptive, well-structured, innovative, reliable, and tailored for Instagram. Photo styles and influencers' suitability positively associate with photo perceptions and purchase intention. Furthermore, followers know what kind of material the influencer has posted before. If the current post is not consistent with the previous post style, followers will respond negatively [41].

Post Frequency: When selecting an influencer profile, make sure to check how often the influencer posts content. Influencers connect with their fans using the posts they share. Influencers must engage their followers by posting high-quality content regularly on their Instagram to build a loyal following. A successful Instagram profile should preferably post content every 1-3 days. Influencer behavior on social media has an effect on the availability of recipients to engage with influencer content. Research indicates that a high social media usage level is more likely to be posted because it is considered more up-to-date. This is one of the strategies widely used by advertisers to approach influencers with many followers to achieve high reach while also considering the degree of activity and engagement is also important [42]. The frequency of posts on social media plays a major role in building trust and improving an influencer's reputation. Studies show a significant connection between the frequency of uploads and balanced self-disclosure to be trusted in the social media world [43]. Apart from that, a company 
should also examine how many influencers post endorsed content. Influencers need to provide a good balance between sponsored and non-sponsored content. If an influencer has written three or more sponsored posts in a row, their reputation could be at risk. The message you wish to send with digital media campaigns should not be pushed too much on consumers by publishing too many posts about the goods or services being advertised. Having sponsored posts with a fair frequency will help preserve the influencer's authenticity instead of only prioritizing commercialism [44].

KPI in Practical Use: Visually, the KPI above that will be compared is grouped in Table 1. After determining the metrics from the literature review, a questionnaire is given to the respondents in order to find what is the most important KPI in practical use. The scale used in this study is a scale of 1 to 9 , with further explanation in Table 2. The respondents' assessment results then calculated using geometric mean to obtain the relative importance value.

Table 1 Criteria and Sub-Criteria for Choosing Influencer

\begin{tabular}{lll}
\hline \multicolumn{1}{c}{ No. } & \multicolumn{1}{c}{ Criteria } & \multicolumn{1}{c}{ Sub-Criteria } \\
\hline \multirow{3}{*}{1} & \multirow{3}{*}{ Community } & Audience Authenticity (C1) \\
& & Audience Reachability (C2) \\
& \multirow{3}{*}{ Interaction } & Followers (C3) \\
\hline \multirow{3}{*}{3} & Rate Card & Engagement Rate (I1) \\
& & Like-Comment Ratio (I2) \\
& & Like-Spread (I3) \\
\hline \multirow{3}{*}{4} & Value of Influencer & Price per Post (RC1) \\
& & Authenticity (VI1) \\
& & Content Quality (VI2) \\
& & Posting Frequency (VI3) \\
& & Relevance (VI4) \\
\hline
\end{tabular}

Table 2 Fundamental Scale Explanation

\begin{tabular}{cll}
\hline Scale & \multicolumn{1}{c}{ Definition } & \multicolumn{1}{c}{ Explanation } \\
\hline 1 & Equal importance & Two activities contribute equally to the objective \\
\hline 3 & Moderate Importance & $\begin{array}{l}\text { Experience and judgment slightly favor one } \\
\text { activity over another }\end{array}$ \\
\hline 5 & Strong Importance & $\begin{array}{l}\text { Experience and judgment strongly favor one } \\
\text { activity over another }\end{array}$ \\
\hline 9 & $\begin{array}{l}\text { Very strong or demonstrated } \\
\text { importance }\end{array}$ & $\begin{array}{l}\text { An activity is favored very strongly over another; } \\
\text { its dominance demonstrated in practice }\end{array}$ \\
\hline $2,4,6,8$ & $\begin{array}{l}\text { Foreme importance } \\
\text { values }\end{array}$ & $\begin{array}{l}\text { The evidence favoring one activity over another is } \\
\text { of the highest possible order of affirmation }\end{array}$ \\
\hline
\end{tabular}

The respondents' assessment results then calculated using geometric mean to derive the relative significance value. After calculating the geometric

Table 3. Table 4 demonstrates the calculation of the priority value (eigenvector) of each criterion from pairwise comparisons. It indicates that the first rank of the most relevant metrics is Group (C) weights 0.458 , followed by the Engagement criterion (I) weighs 0.344, mean, the geometric mean measurement value is used as a reference to a pairwise matrix generated for each criterion shown in

Rate Card (RC) weighs 0.110 , and Importance of Influencer (VI) weighs 0.087 respectively. Under the condition that the acceptable pairwise comparison outcomes have an inconsistency value of not more than 0.10 , so the pairwise comparison with this standard is acceptable since it indicates an inconsistency value of 0.07147. The same steps are repeated to each category to find the most important sub-categories. Finally, a supermatrix is formed to see the global weight of each metrics to evaluate the most important metrics according to marketing practitioners. 
Table 3 Pairwise Matrix for Each Criterion

\begin{tabular}{|c|c|c|c|c|}
\hline Criteria & C & I & RC & VI \\
\hline Community (C) & 1.0 & 2 & 4.419 & 3.332 \\
\hline Interaction (I) & 0.5 & 1.0 & 4.677 & 4.06 \\
\hline Rate Card (RC) & 0.226 & 0.213 & 1.0 & 2 \\
\hline Value of Influencer (VI) & 0.300 & 0.245 & 0.5 & 1.0 \\
\hline
\end{tabular}

Table 4 Pairwise Matrix Eigenvector Values

\begin{tabular}{|c|c|}
\hline \multicolumn{2}{|c|}{ Inconsistency $\mathbf{0 . 0 7 1 4 7}$} \\
\hline Criteria & Weight \\
\hline Community & 0.458 \\
\hline Interaction & 0.344 \\
\hline Rate Card & 0.110 \\
\hline Value of Influencer & 0.087 \\
\hline
\end{tabular}

\section{Referring to}

Table 5, the three most important key performance metrics are followers, like-comment ratio, and audience reachability. This finding is in line with previous studies that indicate that most digital marketing practitioners focus on quantitative key performance measures that are quickly obtained from Instagram metrics, such as the number of interactions and affordability, to assess marketing practices linked to influencers [45].

This study also reveals that recently professionals see the number of followers and the high level of engagement and recognize the influencer's audience's authenticity. Nowadays, many people quickly raise their metrics artificially by purchasing followers, likes, and comments for their benefit. The ratio of likes and feedback (I2) indicates if the influencer does influence the audience. The high reachability also reveals that the influencer may not have many suspicious accounts followers, which suggests an artificially growing number of followers. The high accessibility of the audience makes high leads or future customers as well [46].

Table 5 KPI Importance Ranking

\begin{tabular}{ccc}
\hline Sub-Criteria & Global Weight & Rank \\
\hline Followers (C3) & 0.264394 & 1 \\
\hline Like-Comment Ratio (I2) & 0.210064 & 2 \\
\hline Audience Reachability (C2) & 0.116525 & 3 \\
\hline Price per Post (RC1) & 0.110086 & 4 \\
\hline Like-Spread (I3) & 0.087629 & 5 \\
\hline Audience Authenticity (C1) & 0.077984 & 6 \\
\hline Engagement Rate (I1) & 0.046396 & 7 \\
\hline Relevance (VI4) & 0.045642 & 8 \\
\hline Authenticity (VI1) & 0.020748 & 9 \\
\hline Content Quality (VI2) & 0.014847 & 10 \\
\hline Posting Frequency (VI3) & 0.005686 & 11
\end{tabular}

\section{CONCLUSION}

According to digital marketers, the three most important key performance metrics are followers, likecomment ratio, and audience reachability. This finding is in line with previous studies that indicate that most digital marketing practitioners focus on quantitative key performance measures that are quickly obtained from Instagram metrics, such as the number of interactions and affordability, to assess marketing practices linked to influencers.

In choosing influencers for digital marketing promotion, the KPIs that are considered the community that an influencer has (Community), the experiences that exist on the influencer page (Interaction), the costs for interacting with an influencer (Rate Card), and the qualities held by the influencer (Value of Influencer) (Value of Influencer). In practical use in Indonesia, the most important parameters in choosing influencers for 
digital marketing promotion are Community, Interaction (I), Rate Card (RC), and in the last order is Value of Influencer (VI).

\section{REFERENCES}

[1] S. Kemp, "Digital in Indonesia: All The Statistics You Need in 2021," 11 February 2021. [Online]. Available:

https://datareportal.com/reports/digital-2021indonesia. [Accessed 24 February 2021].

[2] D. M. Scott, The New Rules of Marketing and PR: How to Use Social Media, Online Video, Mobile Applications, Blogs, News Releases, and Viral Marketing to Reach Buyers Directly, John Wiley \& Sons, 2015.

[3] M. De Veirman, V. Cauberghe and L. Hudders, "Marketing Through Instagram Influencers: The Impact of Number of Followers and Product Divergence on Brand Attitude," International Journal of Advertising, vol. 36, no. 5, pp. 798-828, 2017.

[4] N. Segev, N. Avigdor and E. Avigdor, "Measuring Influence on Instagram: A Network-Oblivious Approach," 2018.

[5] A. M. Kaplan and M. Haenlein, "User of the world, unite! The challenges and opportunities of Social Media," Business Horizons, vol. 53, no. 1, pp. 59-68, 2010.

[6] J. H. Kietzmann, K. Hermkens, I. P. McCarthy and B. S. Silvestre, "Social media? Get serious! Understanding the functional building blocks of social media," Business Horizons, vol. 54, no. 3, pp. 241-251, 2011.

[7] S. S. Abed, Y. K. Dwivedi and M. D. Williams, "Social Media as a Bridge to E-commerce Adoption in SMEs: A Systematic Literature Review," The Marketing Review, vol. 15, no. 1, pp. 39-57, 2015.

[8] A. Alalwan, N. Rana, R. Algharabat and A. Tarhini, "A Systematic Review of Extant Literature in Social Media in the Marketing Perspective," Swansea, United Kingdom, 2016.

[9] A. K. Rathore, P. V. Ilavarasan and Y. K. Dwivedi, "Social Media Content and Product Co-Creation: An Emerging Paradigm," Journal of Enterprise
Information Management, vol. 29, no. 1, pp. 7-18, 2016.

[10] K. Usher, C. Woods, E. Casella, N. Glass, R. Wilson, L. Mayner, D. Jackson, J. Brown, E. Duffy, C. Mather, E. Cummings and P. Irwin, "Australian Health Professional Student Use of Social Media," Collegian, vol. 21, no. 2, pp. 95 $101,2014$.

[11] B. Zen and R. Gerritsen, "What Do We Know About Social Media in Tourism? A Review," Tourism Management Perspectives, vol. 10, pp. 27-36, 2014.

[12] Y.-Q. Zhu and H.-G. Chen, "Social Media and Human Need Satisfaction: Implications for Social Media Marketing," Business Horizons, vol. 58, no. 3, pp. 335-345, 2015.

[13] D. Barefoot and J. Szabo, Friends with Benefit: A Social Media Marketing Handbook, No Starch Press, Inc., 2010.

[14] R. Williams, The Influencer Economy, Ryno Lab, 2016, pp. 158-160.

[15] M. Swant, "Twitter says users now trust influencers nearly as much as their friends," 2016. [Online]. Available: http://www.adweek.com/digital/twitter-saysusers-now-trust-influencers-nearly-much-theirfriends-171367/. [Accessed 0909 2019].

[16] S. Barker, "6 of the Most Effective Types of Influencer Collaborations," 2018. [Online]. Available: https://shanebarker.com/blog/effective-typesinfluencer-collaborations/. [Accessed 0909 2019].

[17] Grin, "Influencer Advertising — Everything You Need to Know," 2019. [Online]. Available: https://grin.co/blog/influencer-advertising/. [Accessed 0909 2019].

[18] J. Gross and F. Wangheim, "The Big Four of Influencer Marketing: A Typology of Influencers," Marketing Review St. Gallen, vol. 2, pp. 30-38, 2018.

[19] C. Newberry, "44 Instagram Stats That Matter to Marketers in 2021," Hootsuite, 06 January 2021. [Online]. Available: https://blog.hootsuite.com/instagram-statistics/. [Accessed 24 February 2021]. 
[20] H. Virtanen, P. Björk and E. Sjöström, "Follow for Follow: Marketing of a Start-Up Company on Instagram," Journal of Small Business and Enterprise Development, vol. 24, no. 3, 2017.

[21] A. Lua, "The Ultimate Guide to Instagram Analytics: Metrics, Insights, Tools, and Tips," 2020. [Online]. Available: https://buffer.com/library/instagram-analytics/. [Accessed 1701 2021].

[22] D. Lind, W. Marchal and S. Wathen, Statistical Techniques in Business and Economics, 16th ed., New York: McGraw-Hill International Edition, 2015 .

[23] R. V. Kozinets, S. J. S. Wilner and K. de Valck, "Networked Narratives: Understanding Word-ofMouth Marketing in Online Communities," Journal of Marketing, vol. 74, pp. 71-89, 2010.

[24] S.-A. A. Jin and J. Phua, "Following Celebrities' Tweets About Brands: The Impact of TwitterBased Electronic Word-of-Mouth on Consumers' Source Credibility Perception, Buying Intention, and Social Identification With Celebrities," Journal of Advertising, vol. 43, no. 2, pp. 181-195, 2014.

[25] G. Scott, "More Than Friends: Popularity on Facebook and Its Role in Impression Formation," Journal of Computer-Mediated Communication, vol. 19, pp. 358-372, 2014.

[26] S. Utz, "Show Me Your Friends and I Will Tell You What Type of Person You Are: How One's Profile, Number of Friends, and Type of Friends Influence Impression Formation on Social Network Sites," Journal of Computer-Mediated Communication, vol. 15, pp. 314-335, 2010.

[27] M. Saravanakumar and T. Suganthalakshmi, "Social Media Marketing," Life Science Journal, vol. 9, no. 4, pp. 4444-4451, 2012.

[28] A. Komok, "Audience Reachability and Authenticity," 2020. [Online]. Available: https://help.hypeauditor.com/en/articles/2771675audience-reachability-and-authenticity. [Accessed 0307 2020].

[29] trendHERO, "Audience Type," 2020. [Online]. Available: https://support.trendhero.io/article/58audience-type. [Accessed 2012 2020].

[30] HypeAuditor, "Likes-Comment Ratio," 2020. [Online].

Available: https://help.hypeauditor.com/en/articles/2774398likes-comment-ratio.

[31] trendHERO, "Likes Spread," 2020. [Online]. Available: https://support.trendhero.io/article/57like-spread. [Accessed 0907 2020].

[32] C. C. Childers, L. L. Lemon and M. G. Hoy, "\#Sponsored \#Ad: Agency Perspective on Influencer Marketing Campaigns," Journal of Current Issues \& Research in Advertising, vol. 1, no. 17, pp. 258-274, 2018.

[33] A. Neves, R. Vieira, F. Mourão and L. Rocha, "Quantifying Complementarity Among Strategies for Influencers' Detection on Twitter," Procedia Computer Science, vol. 51, pp. 2435-2444, 2015.

[34] H. A. Schwartz, J. C. Eichstaedt, M. L. Kern, L Dziurzynski, S. M. Ramones, M. Agrawal, A. Shah, M. Kosinski, D. Stillwell, M. E. P. Seligman and L. H. Ungar, "Personality, Gender, and Age in the Language of Social Media: The OpenVocabulary Approach," PloS one, vol. 8, no. 9, 2013.

[35] D. Bakker, "Conceptualising Influencer Marketing," Journal of Emerging Trends in Marketing and Management, vol. I, no. 1, pp. 7987, 2018.

[36] M. B. Beverland and F. J. Farrelly, "The quest for authenticity in consumption: Consumers' purposive choice of authentic cues to shape experienced outcomes," Journal of Consumer Research, vol. 36, no. 5, pp. 838-856, 2010.

[37] L. I. Labrecque, E. Markos and G. R. Milne, "Online Personal Branding: Processes, Challenges, and Implications," Journal of Interactive Marketing, vol. 25, pp. 37-50, 2011.

[38] J. G. Moulard, R. D. Raggio and J. A. G. Folse, "Brand Authenticity: Testing the Antecedents and Outcomes of Brand Management's Passion for its Products," Psychology \& Marketing, vol. 33, no. 6, pp. 421-436, 2016.

[39] J. Napoli, S. J. Dickinson, M. B. Beverland and F. Farrelly, "Measuring consumer-based brand authenticity," Journal of Business Research, vol. 67, no. 6, pp. 1090-1098, 2014.

[40] N. Enke and . N. S. Borchers, "Social Media Influencers in Strategic Communication: A Conceptual Framework for Strategic Social Media Influencer Communication," International 
Journal of Strategic Communication, vol. 13, no. 4, pp. 261-277, 2019.

[41] E. Pöyry, M. Pelkonen, E. Naumanen and S.-M. Laaksonen, "A Call for Authenticity: Audience Responses to Social Media Influencer Endorsement in Strategic Communication," International Journal of Strategic Communication, vol. 13, no. 4, pp. 336-351, 2019.

[42] A. T. Stephen, Y. Dover, L. Muchnik and J. Goldenberg, "Pump it Out! The Effect of Transmitter Activity on Content Propagation in Social Media," Saïd Business School WP, vol. 1, 2017.

[43] V. Dennen, "Becoming a Blogger: Trajectories, Norms, and Activities in a Community of Practice," Computers in Human Behavior, vol. 36, pp. 350-358, 2014.
[44] A. Moore, K. Yang and H. M. Kim, "Influencer Marketing: Influentials' Authenticity, Likeability and Authority in Social Media," Cleveland, Ohio, 2018.

[45] J.-F. Gräve, "What KPIs Are Key? Evaluating Performance Metrics for Social Media Influencers," Social Media + Society, vol. 5, no. 3, pp. 1-9, 2019.

[46] M. Haenlein, r. Anadol, T. Farnsworth, H. Hugo, J. Hunichen and D. Welte, "Navigating the New Era of Influencer Marketing: How to be Successful on Instagram, TikTok, \& Co.," California Management Review, vol. 63, no. 1, pp. 5-25, 2020. 